\title{
THE CRITICAL ROLE OF ADVANCED SUSTAINABILITY ASSESSMENT TOOLS IN ENHANCING THE REAL-WORLD APPLICATION OF BIOFUELS
}

\author{
Meisam Tabatabaei* \\ Institute of Tropical Aquaculture and Fisheries (AKUATROP), Universiti Malaysia Terengganu \\ 21030 Kuala Nerus, Terengganu, Malaysia \\ Biofuel Research Team (BRTeam), Terengganu, Malaysia \\ Microbial Biotechnology Department, Agricultural Biotechnology Research Institute of Iran (ABRII), Agricultural \\ Research, Extension, and Education Organization (AREEO), Karaj, Iran, meisam_tab@yahoo.com \\ (D) https://orcid.org/0000-0001-8067-1944

\section{Mortaza Aghbashlo*} \\ Department of Mechanical Engineering of Agricultural Machinery, Faculty of Agricultural Engineering \\ and Technology, College of Agriculture and Natural Resources, University of Tehran, Karaj, Iran \\ maghbashlo@ut.ac.ir \\ https://orcid.org/0000-0001-8534-4686
}

\begin{abstract}
Sustainability has become of paramount importance in the biofuel industry. Accordingly, various sustainability assessment schemes such as emergy analysis, techno-economic analysis, life cycle assessment, energy accounting, and exergy analysis and its extensions (exergoeconomic, exergoenvironmental, and exergoeconoenvironmental analyses) are being employed increasingly for decision-making on biofuel production and consumption systems. In this opinion paper, after classifying and describing biofuel generations, the developed sustainability assessment tools are critically explained, and their pros and cons are discussed. Overall, among the various sustainability assessment approaches introduced so far, exergy-based methods appear to be the most promising tools for developing sustainable biofuel systems. This can be attributed to the fact that the exergy concept is deeply rooted in the well-defined principles of thermodynamics.
\end{abstract}

\section{Keywords}

biofuels; sustainability; exergy; emergy; Life Cycle Assessment; decision-making

Fossil fuels are currently the major sources of energy globally, and this is unlikely to change anytime soon. On the other hand, pursuing the business-as-usual scenario is regarded as a serious threat to our entire species. This is mainly ascribed to the increasing atmospheric concentration of greenhouse gases (GHGs) contributed by fossil fuels. The resultant unfavorable phenomena, i.e., global warming and climate change, have already endangered public health from different perspectives and could profoundly affect the life of a child born today [1].

Various types of renewable energies have been at the center of attention for quite some time now, intending to mitigate the tragedy by reducing the global share of carbon-intensive energy carriers. However, their penetration into the transportation sector has been trivial. This sector requires $5.6 \times 10^{20} \mathrm{~J} / \mathrm{yr}(560 \mathrm{EJ} / \mathrm{yr})$, accounting for $30 \%$ of the world's fossil fuel annual consumption [2]. Substituting fossil fuels with their renewable counterparts at such a huge scale is a major challenge. Moreover, most renewable energy carriers such as solar energy and wind energy can hardly be considered as short-term or even mid-term solutions, given their current intrinsic technological limitations. Hence, among the existing options, biofuels such as bioethanol and biodiesel seem to be the most promising alternatives to at least partially replace their carbon-intensive fossil-oriented counterparts, i.e., gasoline and diesel, respectively.

Biofuels are less carbon-intensive vs. fossil fuels. For instance, biodiesel combustion lowers unburned hydrocarbon, carbon monoxide, and smoke emissions by $20 \%, 30 \%$, and $50 \%$, respectively, compared with mineral diesel [3]. From the global warming perspective, it should also be highlighted that the carbon emitted through the combustion of biofuels is of biogenic origin and hence, does not contribute to the long carbon cycle also known as the geogenic carbon cycle. Combustion of each liter of mineral diesel, for instance, leads to the

https://doi.org/10.32933/Actalnnovations.37.6•ISSN 2300-5599 • C 2020 RIC Pro-Akademia - CC BY 
emission of $2.67 \mathrm{~kg}$ of $\mathrm{CO}_{2}$ of geogenic origin, which could be entirely prevented by using biodiesel [4]. Biofuels are also advantageous from the application point of view for several reasons; 1) they share similar physicochemical properties with fossil fuels, 2) they can be used in in-use engines with little or no modifications, 3) they are indigenously available, among others.

Despite the above-mentioned promising features, biofuels, and in particular, their first-generation, have also been criticized for their sustainability features. First-generation biofuels amounting to over $95 \%$ of the global biofuel production are produced from edible resources, e.g., corn bioethanol and soybean biodiesel [5]. Despite their economic viability in geographical locations with abundant fertile lands and water resources, their sustainability is heavily questioned, citing their land-use change (LUC) and the resultant contribution to the net flux of carbon to the atmosphere [6]. In addition to that, by diverting edible resources with food and feed applications to the biofuel industry, global food security has been more than ever threatened. Biofuels production has been widely criticized for its unfavorable impact on crop prices and contribution to hunger [7]. These shortcomings place first-generation biofuels in conflict with the United Nations' Sustainable Development Goals (SDGs) and particularly SDG 2. These downsides have been the main motivation for the shift from firstgeneration biofuels to the next generations.

From the sustainability point of view, the most comprehensive classification of biofuels was presented by Hajjari et al. [8], based on which a distinction was made between non-edible resources or biomass (Figure 1). More specifically, non-edible energy crops were designated as feedstocks resulting in the production of secondgeneration biofuels, while waste-oriented resources such as waste cooking oil (WCO) and bagasse were identified as feedstocks associated with the third-generation biofuels [3]. It should be noted that although the non-edible energy crops pose no apparent threat to global food security, they are no different from their first-generation counterparts from the LUC and water security perspectives unless cultivated on marginal lands and through non-agricultural water resources. However, even under the latter circumstances and to achieve the maximal yields, non-edible energy crops are still associated with environmental burdens arising from carrying out the routine agricultural practices such as fertilizer application, harvest, and transfer. On the contrary, thirdgeneration feedstocks are simply the different sources of waste generated through completely different processes and are therefore attributed to no upstream GHG emissions nor carbon footprints. While such a comparison is largely accurate but it overlooks an important feature of non-edible energy crops; i.e., soil and root carbon storage contribution. In a recent investigation, Yang and Tilman [9] proved that soil and root carbon storage contributed by these crops (especially high plant diversity mixtures) is the main source of GHG savings rather than fossil fuel displacement. They argued that the former removes $\mathrm{CO}_{2}$ from the atmosphere directly, whereas the latter benefit stems from the avoidance of future fossil fuel GHG emissions, a pathway that is dependent on a wide array of assumptions and uncertainties, especially the rebound effect of the fuel market [9].

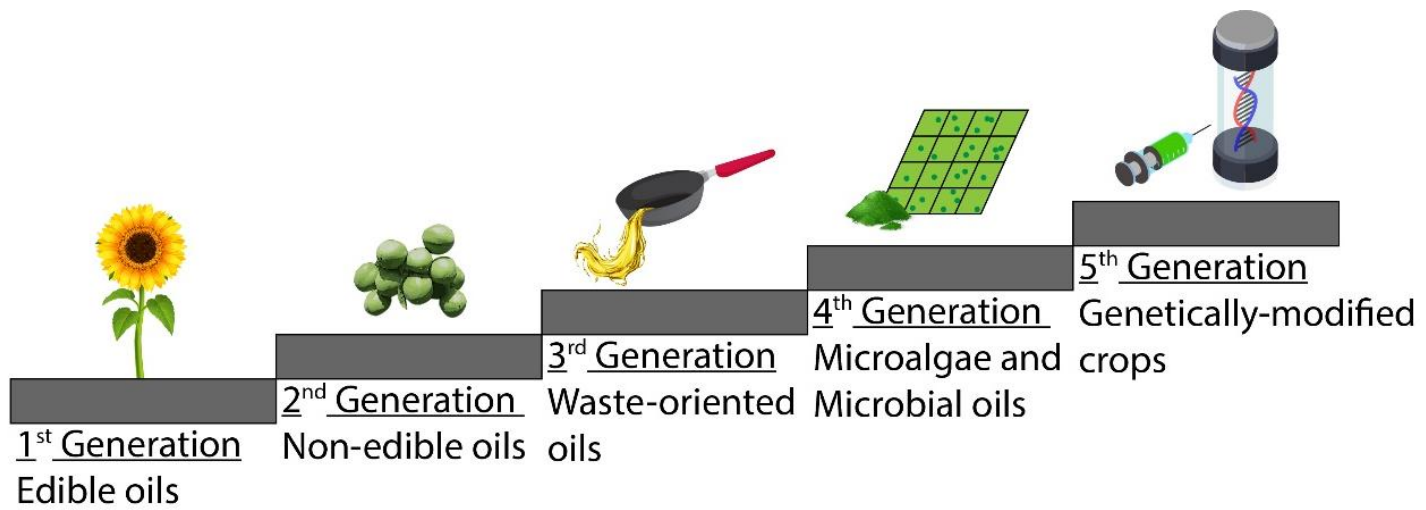

Fig. 1. Biofuel classification from the sustainability point of view. Source: Adapted from Hajjari et al. [8]. 
It is also important to note that to take full advantage of the carbon storage benefits of non-edible energy crops, they should be cultivated on marginal lands and irrigated by non-conventional water resources. This could be simply justified by taking into account the adverse impacts of LUC on the carbon intensity of the whole process. It has been documented that LUC caused by the cultivation of non-edible energy crops could contribute to the emission of 17 to 420 times more $\mathrm{CO}_{2}$ than the yearly GHG mitigations expected via fossil fuel displacement [10$12]$.

As mentioned earlier, third-generation feedstocks are not associated with any upstream environmental burdens; however, it should not be overlooked that they generally require further processing instead to be quality-wise on par with their first- and second-generation counterparts. Such further processing is attributed to some material and energy inputs and, therefore, imposes some environmental burdens. For instance, WCO should undergo physical filtration to eliminate food debris, followed by de-watering and esterification to remove water and free fatty acid contents, respectively, before it can be introduced into a feasible transesterification process [13]. On the contrary, soybean oil (first-generation feedstock) and non-edible safflower oil (second-generation feedstock) do not require such pretreatments. Therefore, the use of waste-based resources for biofuel production should also be thoroughly scrutinized from the sustainability perspectives using advanced sustainability assessment tools.

The fourth- and fifth-generation biofuels are generated from microalgae and genetically-engineered crops and algae, respectively. Despite the promising features of these generations from the sustainability perspective, on most occasions, the costs of the biofuels produced are not competitive yet [14]. In light of that, recent efforts have been largely dedicated to developing multi-products biorefinery systems to mitigate the challenges faced and enhance the economic feasibility of these generations of biofuels [15]. For instance, in a recent work, Kim et al. [16] presented an innovative closed-loop biorefinery process by integrating the use of low-recalcitrant engineered biomass with its pretreatment using lignin-derived deep eutectic solvents. The authors reported that the integrated process led to near-theoretical sugar yields.

Bearing in mind the above arguments, any decision-making and subsequent expansion of the biofuel industry should be subject to a thorough sustainability assessment ensuring that the various aspects of a production cycle will be taken into account. Advanced sustainability assessment tools such as emergy analysis, techno-economic analysis, life cycle assessment (LCA), energy, and exergy analysis and its subsidiaries (exergoeconomic, exergoenvironmental, and exergoeconoenvironmental analyses) are promising approaches to serve that purpose $[17,18]$.

The emergy concept is based on two main pillars, i.e., systems ecology rooted in general systems theory and biophysical principles governing the systems [19]. Emergy is developed to quantify the available energy previously used in direct and indirect forms in creating a good or service [20]. This long-run sustainability assessment tool can adequately evaluate the environmental burdens caused by a good or service [17]. Using transformities (i.e., unit solar-equivalent Joule), all kinds of support to a system under investigation, including energetic/non-energetic and material/non-material fluxes, are converted into a homogeneous unit, i.e., solar emjoule (sej) [21]. The total environmental production cost of a good or service is obtained by summing the emergy values of all inflows, which are obtained by multiplying their quantities by the corresponding transformities [21]. The most critical step of an emergy analysis is to choose the proper transformity coefficients being used to express all influxes in solar energy equivalents [17]. Like other sustainability indicators, the emergy concept suffers from its conceptual and methodological limitations [22]. The majority of the issues associated with this method, including inaccuracy, irreproducibility, inconsistency, and incompleteness, can be effectively addressed by mimicking the inventory modeling fundamentals of the LCA methodology.

Techno-economic analysis is one of the best ways to assess and compare the economic viability and profitability of energy projects through identifying their short- and long-term outcomes [18]. This method includes hints to address technical and economic bottlenecks of newly emerged energy technologies that could pave the way for their commercialization. However, this analysis does not consider the thermodynamic and environmental aspects of energy systems, rendering it susceptible to offering misleading recommendations and conclusions [18].

https://doi.org/10.32933/ActaInnovations.37.6•ISSN 2300-5599 • C 2020 RIC Pro-Akademia - CC BY 
LCA is one of the most popularized methodologies to assess the environmental impacts associated with making and using a good or service over its entire life cycle [23]. This approach can track the cradle-to-grave environmental consequences of a good or service, i.e., from raw material extraction to product manufacturing, distribution, use, maintenance, recycling, and disposal [24]. An LCA analysis is started by gathering the relevant inflows and outflows of a system under investigation, proceeded by quantifying their related environmental burdens, and completed by translating and interpreting the outcomes of the inventory analysis and impact assessment stages [25]. LCA methodology can offer a broad spectrum of insights on natural resource consumption, climate change, human health, and ecological degradation associated with a good or service [26]. Nevertheless, subjectivity, inaccuracy, uncertainty, and variability are the main inherent problems of this approach [17].

The first law-based energy analysis is one of the most extensively applied approaches for measuring and comparing the performance of energy conversion systems. Despite the useful information provided by this analysis, it fails to account for the quality loss of energy caused by internal irreversibilities in thermodynamic processes [27]. Most of the problems, if not all, associated with energy analysis, can be adequately addressed using the exergy concept in which both the quality and quantity of resources are taken into consideration [28]. The thermodynamic property exergy can reliably quantify the upper limit of useful work that can be obtained from an energy system. When the maximum amount of work is produced, the system under consideration reaches a state through reversible processes in which it is in equilibrium with the reference environment. In general, exergy analysis is used to quantify, locate, and interpret the thermodynamic losses of energy conversion systems [29].

Besides, the enhanced versions of exergy analysis, i.e., exergoeconomic and exergoenvironmental approaches, can offer more detailed information about technical, economic, and environmental aspects of energy conversion systems. These approaches can provide a deep understanding of economic costs and environmental impacts associated with equipment and thermodynamic losses, as illustrated in Figure 2 [18]. The exergoeconoenvironmental approach elaborated by Aghbashlo and Rosen [30] can yield further complementary information concerning the thermodynamic, economic, and environmental aspects of energy systems. Advanced analyses developed by Tsatsaronis and Morosuk [31] can also boost the quality of the results obtained from exergy-based approaches by providing extra information about the thermodynamic, economic, and environmental interactions among the units of energy systems. These analyses can also quantify the avoidable portion of the thermodynamic losses, economic costs, and environmental impacts.

Similar to the other available sustainability ranking approaches, the reliability of the results of exergy analysis is substantially influenced by the cut-off criteria specified for the boundaries. Furthermore, the conclusions derived from exergy-based analyses are affected to some extent by the assumptions made regarding the reference conditions. Overall, among the various sustainability rating tools explained above, exergy-based approaches appear to be the most promising tools for developing sustainable biofuel systems. This can be attributed to the fact that the exergy concept is deeply rooted in the well-defined principles of thermodynamics. 


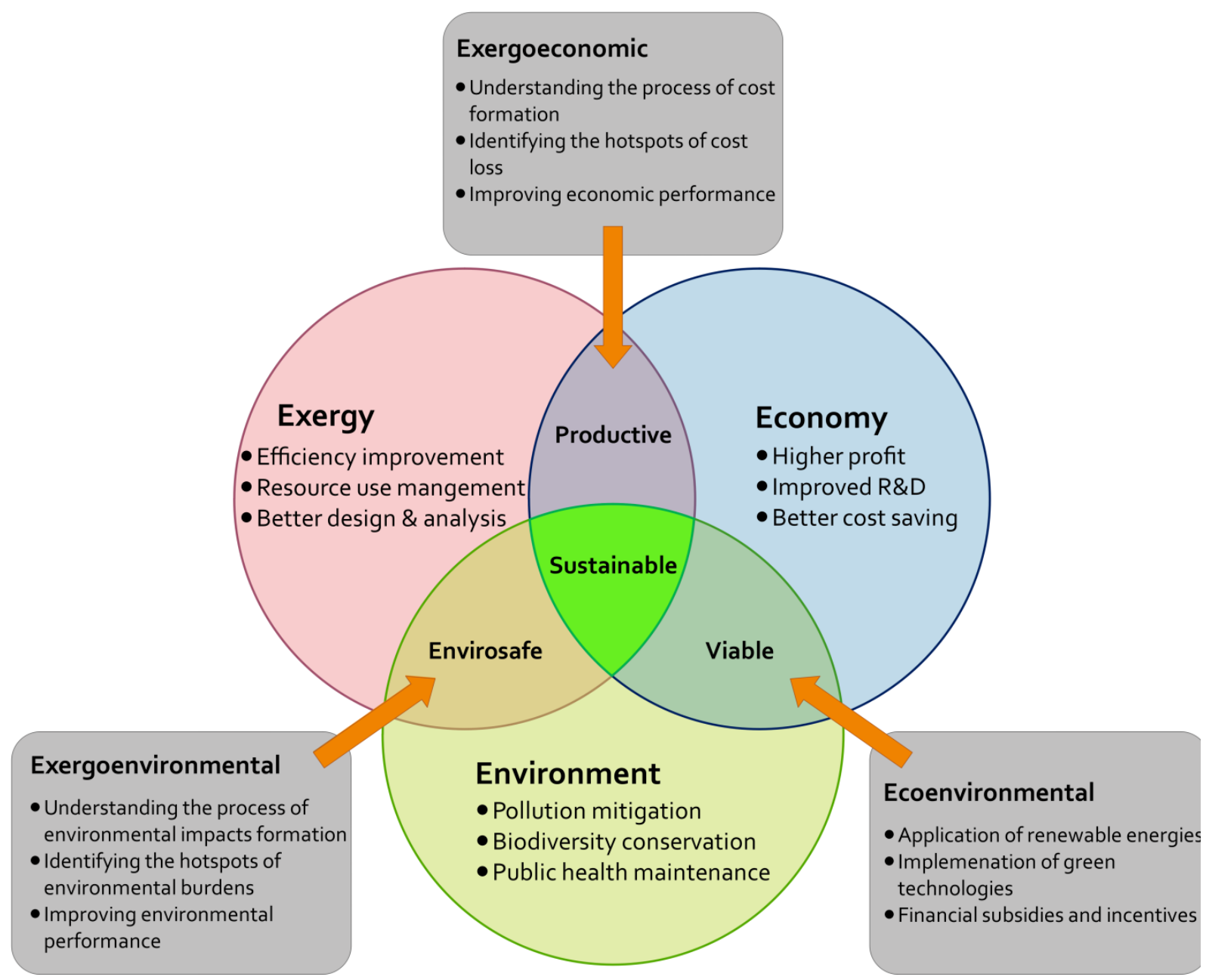

Fig. 2. The interactions among exergy, economy, and environment [18]. With permission from Elsevier. Copyright@ 2020 Elsevier. License Number: 4918831100244.

\section{Impact}

Climate change and its adverse impact on public health are believed to have been driving the world toward an irreversible point, at least as much as our species is concerned. Hence, there has been a growing interest in various strategies aimed at mitigating greenhouse gas emissions, including fossil fuel replacement with alternative energy carriers such as biofuels. To date, different generations of biofuels have been developed, each associated with pros and cons. Accordingly, any decision-making and subsequent expansion of the biofuel industry should be subject to a thorough sustainability assessment ensuring that the various aspects of a production cycle will be taken into account. Advanced sustainability assessment tools such as emergy analysis, techno-economic analysis, life cycle assessment (LCA), energy, and exergy analysis and its subsidiaries (exergoeconomic, exergoenvironmental, and exergoeconoenvironmental analyses) are promising approaches to serve that purpose and are critically discussed in this work.

\section{Conflict of interest}

The authors declare that they have no conflict of interest.

\section{Acknowledgments}

This research has not been supported by any external funding.

\section{References}

[1] Watts N, Amann M, Arnell N, Ayeb-Karlsson S, Belesova K, Boykoff M, Byass P, Cai W, Campbell-Lendrum 
D, Capstick S. The 2019 report of The Lancet Countdown on health and climate change: ensuring that the health of a child born today is not defined by a changing climate. Lancet 394 (2019), 1836-1878.

[2] Hossain MF. Invisible transportation infrastructure technology to mitigate energy and environment. Energy. Sustainability and Society 7 (2017), 1-12.

[3] Hajjari M, Tabatabaei M, Aghbashlo M, Ghanavati H. A review on the prospects of sustainable biodiesel production: A global scenario with an emphasis on waste-oil biodiesel utilization. Renewable and Sustainable Energy Reviews 72 (2017), 445-464.

[4] EPA, U.S. Environmental Protection Agency. Average Carbon Dioxide Emissions Resulting from Gasoline and Diesel Fuel, (2005). https://www.epa.gov/.

[5] Sajjadi B, Aziz A, Raman A, Arandiyan H. A comprehensive review on properties of edible and non-edible vegetable oil-based biodiesel: Composition, specifications and prediction models. Renewable and Sustainable Energy Reviews 63 (2016), 62-92.

[6] Aghbashlo M, Demirbas A, Biodiesel: hopes and dreads, Biofuel Research Journal 3 (2016), 379.

[7] Mitchell D. A note on rising food prices (Policy Research Working Paper 4682), World Bank, Washington, DC. (2008).

[8] Hajjari M, Tabatabaei M, Aghbashlo M, Ghanavati H. A review on the prospects of sustainable biodiesel production: A global scenario with an emphasis on waste-oil biodiesel utilization. Renewable and Sustainable Energy Reviews 72 (2017), 445-464.

[9] Yang Y, Tilman D, Soil and root carbon storage is key to climate benefits of bioenergy crops. Biofuel Research Journal 7 (2020), 1143-1148.

[10] Havlík P, Schneider UA, Schmid E, Böttcher H, Fritz S, Skalský R, Aoki K, De Cara S, Kindermann G, Kraxner F, Global land-use implications of first and second generation biofuel targets. Energy Policy 39 (2011), 5690-5702.

[11] Searchinger T, Heimlich R, Houghton RA, Dong F, Elobeid A, Fabiosa J, Tokgoz S, Hayes D, Yu T-H. Use of US croplands for biofuels increases greenhouse gases through emissions from land-use change. Science 319 (2008), 1238-1240.

[12] Fargione J, Hill J, Tilman D, Polasky S, Hawthorne P. Land clearing and the biofuel carbon debt. Science 319 (2008), 1235-1238.

[13] Aghbashlo M, Hosseinpour S, Tabatabaei M, Mojarab Soufiyan M. Multi-objective exergetic and technical optimization of a piezoelectric ultrasonic reactor applied to synthesize biodiesel from waste cooking oil (WCO) using soft computing techniques. Fuel 235 (2019), 100-112.

[14] Chisti Y. Constraints to commercialization of algal fuels. Journal of Biotechnology 167 (2013), 201-214.

[15] Aghbashlo M, Mandegari M, Tabatabaei M, Farzad S, Mojarab Soufiyan M, Görgens JF, Soufiyan MM, Görgens JF, Mojarab Soufiyan M, Görgens JF. Exergy analysis of a lignocellulosic-based biorefinery annexed to a sugarcane mill for simultaneous lactic acid and electricity production. Energy 149 (2018), 623-638.

[16] Kim KH, Eudes A, Jeong K, Yoo CG, Kim CS, Ragauskas A. Integration of renewable deep eutectic solvents with engineered biomass to achieve a closed-loop biorefinery. Proceedings of the National Academy of Science 116 (2019), 13816-13824.

[17] Rosen MA. Environmental sustainability tools in the biofuel industry. Biofuel Research Journal 5 (2018), 751-752.

[18] Soltanian S, Aghbashlo M, Almasi F, Hosseinzadeh-Bandbafha H, Nizami A-S, Ok YS, Lam SS, Tabatabaei M. A critical review of the effects of pretreatment methods on the exergetic aspects of lignocellulosic biofuels, Energy Conversion and Managment 212 (2020), 112792.

[19] Rótolo CC, Francis C, Ulgiati S. Emergy: A New Approach to Environmental Accounting, Supplement to Chapter 1, in Tow P, Cooper I, Prtridge I, Birch C (Eds.). Rainfed Farming System. Springer (2011), 35-42.

[20] Wei Y, Li Y, Liu X, Wu M. Sustainable development and green gross domestic product assessments in megacities based on the emergy analysis method-A case study of Wuhan. Sustainable Development 28 (2020), 294-307.

[21] Santagata R, Zucaro A, Viglia S, Ripa M, Tian X, Ulgiati S. Assessing the sustainability of urban eco-systems through Emergy-based circular economy indicators. Ecological Indicators 109 (2020), 105859.

[22] Rugani B, Benetto E. Improvements to emergy evaluations by using life cycle assessment. Environmental Science \& Technology 46 (2012), 4701-4712.

[23] Meneses M, Pasqualino JC, Céspedes-Sánchez R, Castells F. Alternatives for reducing the environmental impact of the main residue from a desalination plant, Journal of Industrial Ecology 14 (2010), 512-527.

[24] Ioannidou D, Zerbi S, Habert G. When more is better-Comparative LCA of wall systems with stone. Building and Environment 82 (2014), 628-639.

[25] Dufour J, Iribarren D. Life cycle assessment of biodiesel production from free fatty acid-rich wastes.

https://doi.org/10.32933/Actalnnovations.37.6•ISSN 2300-5599 • (C) 2020 RIC Pro-Akademia - CC BY 
Renewable Energy 38 (2012), 155-162.

[26] Aghbashlo M, Tabatabaei M, Soltanian S, Ghanavati H. Biopower and biofertilizer production from organic municipal solid waste: An exergoenvironmental analysis. Renewable Energy 143 (2019), 64-76.

[27] Patel CD. Sustainable ecosystems: enabled by supply and demand management, in: International Conference on Distributed Computing Networking, Springer, 2011: pp. 12-28.

[28] Rosen MA. Energy efficiency and sustainable development. International Journal of Global Energy Issues 17 (2002), 23-34.

[29] Morosuk T, Tsatsaronis G. A new approach to the exergy analysis of absorption refrigeration machines. Energy 33 (2008), 890-907.

[30] Aghbashlo M, Rosen MA. Exergoeconoenvironmental analysis as a new concept for developing thermodynamically, economically, and environmentally sound energy conversion systems. Journal of Cleaner Production 187 (2018), 190-204.

[31] Tsatsaronis G, Morosuk T. A general exergy-based method for combining a cost analysis with an environmental impact analysis. Part I-theoretical development, in: Proceedings of ASME 2008 International Mechanical Engineering Congress and Exposition. IMECE, Boston, Massachusetts, USA, 2008: p. 67219. 